\title{
Laboratory tests of how selective factors impact the durability and functionality of road safety steel devices
}

\author{
Dariusz Rudnik ${ }^{1, *}$, Adam Klasik ${ }^{1}$, Marcin Grobelny ${ }^{1}$, and Ewa Rostek ${ }^{1}$ \\ ${ }^{1}$ Motor Transport Institute, ul. Jagiellońska 80, 03-301 Warsaw, Poland
}

\begin{abstract}
Road safety devices, such as guides and wire rope barriers have a direct impact on road safety. These devices are mounted close to the road therefore they are exposed to mechanical damage and corrosive factors, which causes them to degrade subsequently leading to adverse changes of the useful properties. The objective of research was to determine the influence of exploitation factors (corrosion, mechanical damage) on the functionality changes of these selected steel road safety elements. Samples for testing mechanical properties were taken from guides and wire rope material in delivery condition and after exposure to a corrosive environment. In order to simulate mechanical damage, samples were cut or holes were made or they were gravelled. In the case of wires taken from ropes, tensile tests of wires subjected to pre-cycles of fatigue load corresponding to cycles of changes in rope stress in operating conditions were also performed.
\end{abstract}

\section{Introduction}

Road safety devices, such as guides and wire rope barriers have a direct impact on road safety. These devices are mainly made of steel, and are mounted close to the road therefore they are exposed to mechanical damage and corrosive factors, which causes them to degrade subsequently leading to adverse changes of the useful properties.

\section{Purpose of research}

The purpose of research was to determine the influence of exploitation factors (corrosion, mechanical damage) when there were changes in the functionality of these selected steel road safety elements. In this research the samples were taken from guides and wire rope barriers which were mechanically damaged and then were assessed and subjected to a corrosive environment.

\footnotetext{
* Corresponding author: dariusz.rudnik@its.waw.p1
} 


\section{Test methods}

In order to identify materials used to produce guides and wire ropes, tests of steel chemical composition were made. Next, the thickness of the zinc layer on the elements was measured. Samples were subjected to mechanical damage (spot hits of stones) according to the test method described in the standard ASTM D 3170-03 [1] (also SAE J-400 [2] or General Motors GMW14700 [3]). Exposure consisted in the application of a specified amount of gravel with known granulation to the surfaces of the samples tested. The gravel was poured into a stream of compressed air and hit the surface of the tested samples at a certain speed at an angle of $90^{\circ}$. Parameters of the test (according to $\mathrm{C}$ method, GMW14700 [3]) were as follows:

- temperature $22^{\circ} \mathrm{C} \pm 5^{\circ} \mathrm{C}$,

- gravel granulation $8 \div 16 \mathrm{~mm}$,

- gravel volume $473 \mathrm{ml} \pm 10 \mathrm{ml}$,

- exposure time $8 \mathrm{~s} \pm 2 \mathrm{~s}$,

- compressed air pressure $480 \mathrm{kPa} \pm 20 \mathrm{kPa}$,

- distance between the outlet and the surface of the sample $349 \mathrm{~mm}$.

After mechanical exposure to impacts of gravel, an assessment was made of the damage to barrier guide samples using an optical profilometer Bruker Contour GT-K1. The highest measured depth of damage to the zinc coating caused by gravel impacts did not exceed 35 $\mu \mathrm{m}$.

Corrosive endangering of samples was performed using ISO 21207 [4], B method, duration up to 5 weeks, in the Ascott CP1000IP corrosion chamber. The examined elements were subjected to five seven-day cycles, each of which consisted of:

- $\quad 2$ hours of exposure of samples to neutral salt spray ( $5 \%$ sodium chloride solution, $\mathrm{pH}$

7,1 , measured at $21^{\circ} \mathrm{C}$ ) at $35^{\circ} \mathrm{C}$, and then 22 hours of drying the samples at $23^{\circ} \mathrm{C}$ and $50 \%$ humidity,

- 48 hours of exposure in an atmosphere containing SO2 (gas volume 5x10-6) and NO2 (gas volume 10-5) and humidity $95 \%$ and temperature $25^{\circ} \mathrm{C}$,

- 2 hours of exposure of samples to neutral salt spray ( $5 \%$ sodium chloride solution, $\mathrm{pH}$ 7,1 , measured at $21^{\circ} \mathrm{C}$ ) at $35^{\circ} \mathrm{C}$, and then 22 hours of drying the samples at $23^{\circ} \mathrm{C}$ and $50 \%$ humidity,

- 72 hours of exposure in an atmosphere containing SO2 (gas volume 5x10-6) and NO2 (gas volume 10-5) and humidity $95 \%$ and temperature $25^{\circ} \mathrm{C}$.

According to ISO 21207 [4], the specified time of corrosive exposure corresponds to the following service life under real conditions:

- $\quad 2$ weeks of exposure - 8 years of operation;

- 3 weeks of exposure - 14 years of operation;

- 5 weeks of exposure - 27 years of operation.

Samples for testing the mechanical properties were taken from guides and wire rope material in delivery condition and after corrosive environment endangering. In order to simulate mechanical damage, the samples were cut and holes were made (Fig. 1.).

Selected mechanical properties were determined on the basis of tensile test results (according to PN-EN ISO 6892-1:2010 [5] obtained from the tests carried out on servohydraulic machines INSTRON 8802 and 8875).

In the case of wires taken from the ropes, tensile tests of wires subjected to pre-cycles of fatigue load corresponding to cycles of changes in rope stress in operating conditions were also performed.

The flow chart for the execution of the tasks is shown in Fig. 2 

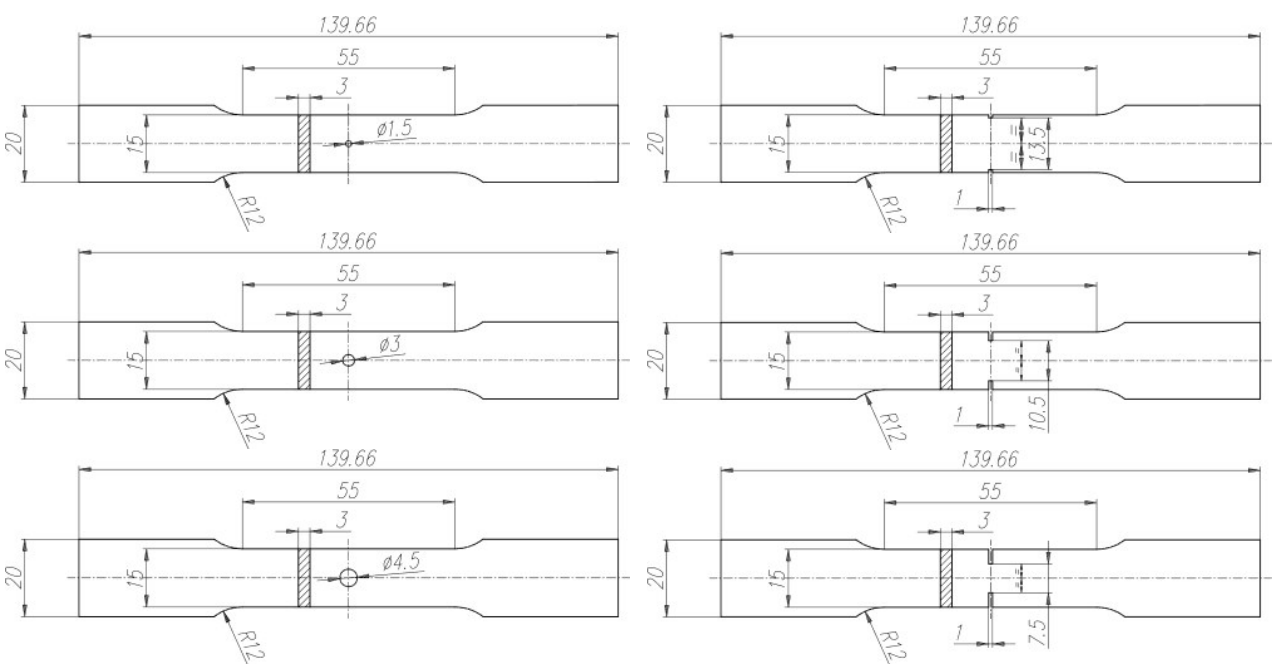

Fig. 1. Dimensions of samples for testing mechanical properties with simulated mechanical damage.

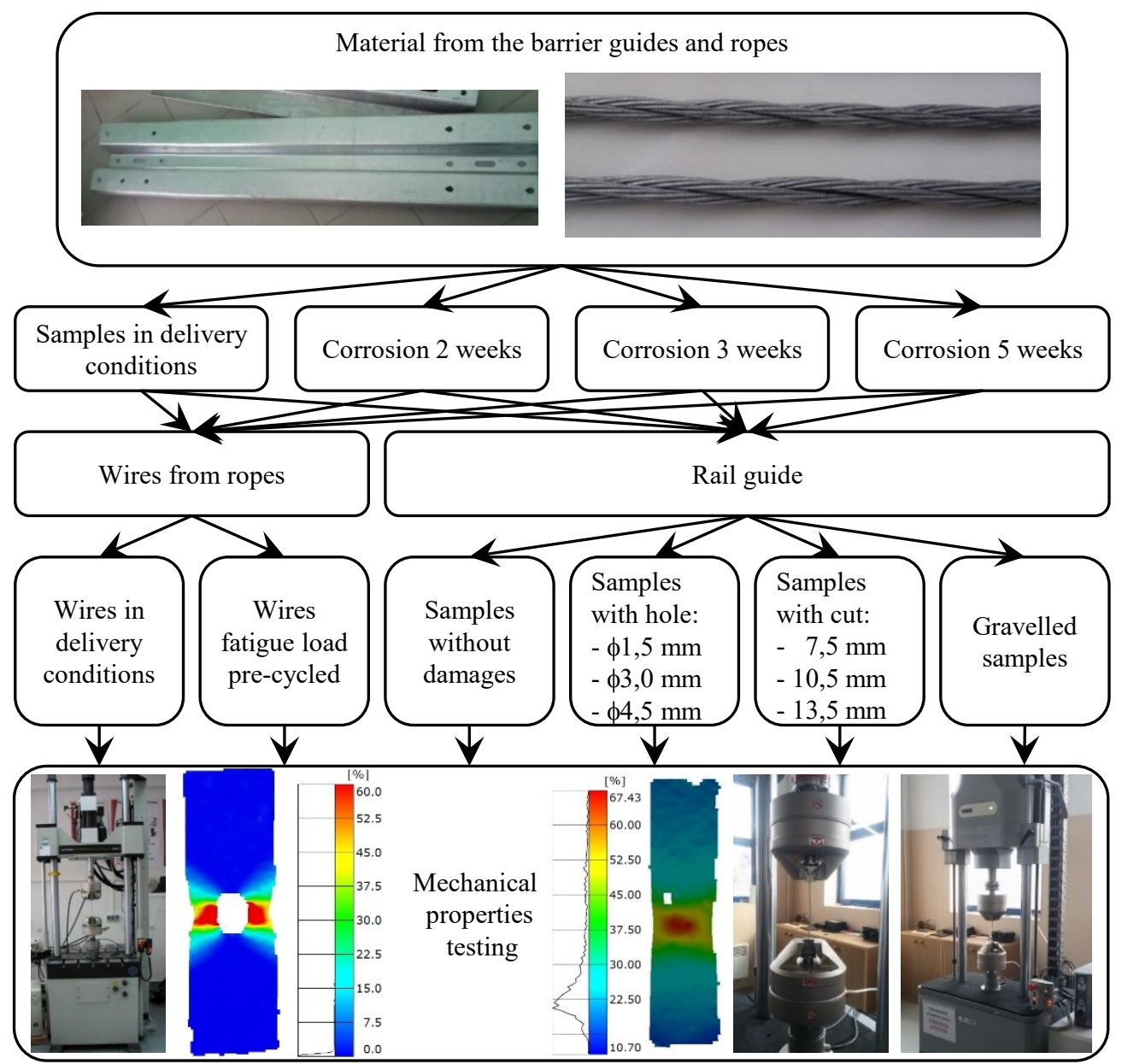

Fig. 2. Flow chart of the tasks. 


\section{Results of research}

For each of the samples taken from the barrier guide in the delivery condition and after exposures (gravel) and mechanical damage (cuts, openings) and subjecting them to a corrosive environment, a tensile test was carried out. An example of a tensile test characteristics is shown in Fig. 3.
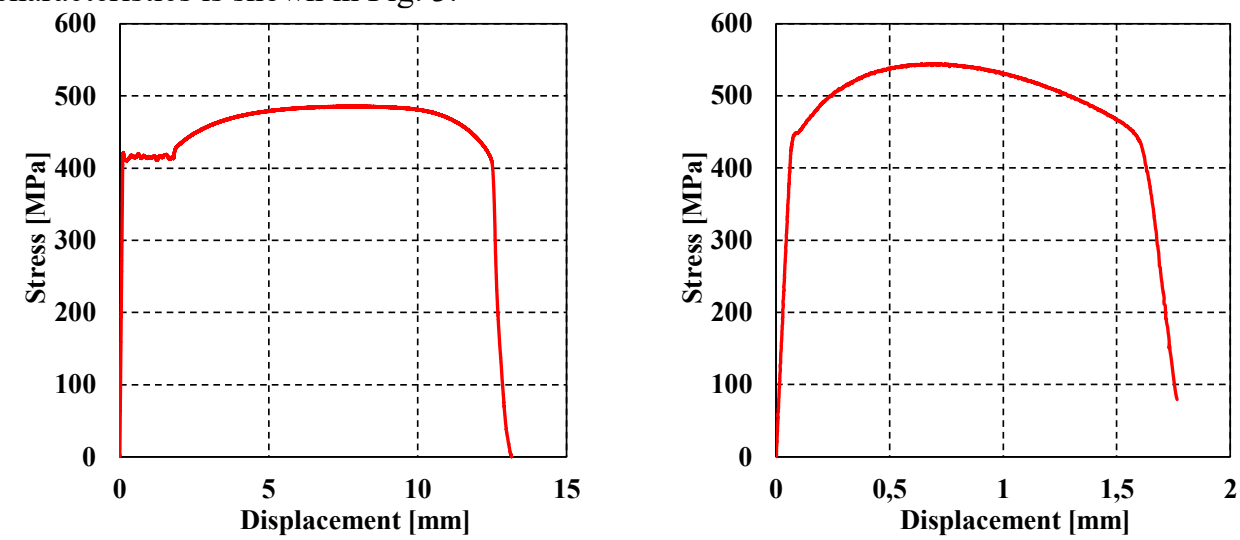

Fig. 3. Tensile test characteristic of samples prepared from the barrier guide - examples of stretching curves.

Fig. 4 shows the results of mechanical properties tests of samples made of the barrier guide bar. They refer to how the samples were damaged (holes, cuts) and the time of corrosive environment endangering.

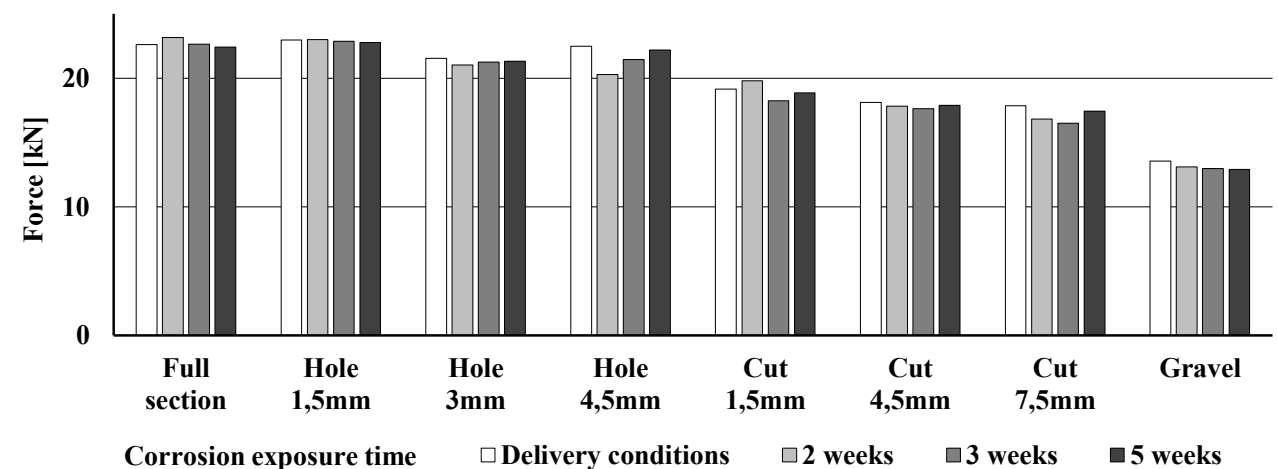

Fig. 4. Test results of mechanical properties of samples made from the barrier guide.

The wire samples taken from the barrier wire rope were divided into two groups. Both groups were subjected to a corrosive environment. Then samples from one group were subjected to fatigue loads. A tensile test was carried out for each of the samples taken from the rope from both groups: in the delivery condition and after subjecting them to a corrosive environment and fatigue loads.

Fig. 5 shows an example of tensile test characteristics.

Fig. 6 shows the results of mechanical properties tests of samples made of barrier rope wires. This refers to mechanical endangering to which the samples were subjected (load fatigue) and the duration of endangering in a corrosive environment. 

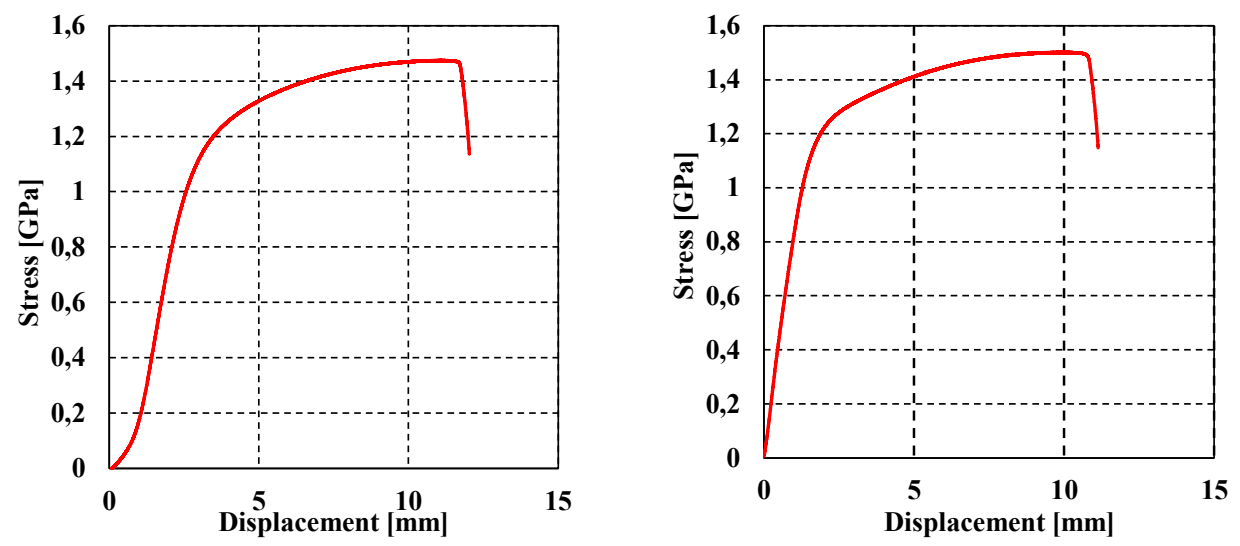

Fig. 5. Mechanical properties of samples prepared from the barrier rope wires - examples of stretching curves.

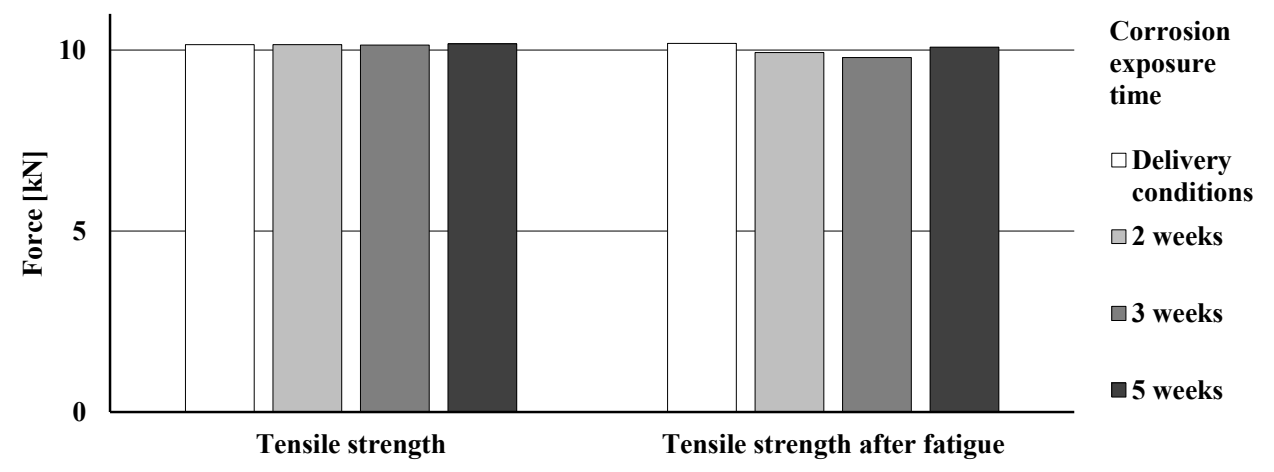

Fig. 6. Mechanical properties of samples prepared from the barrier rope wires - examples of stretching curve.

\section{Conclusions}

The results help to formulate the following conclusions:

- The endangering of the barrier guide covered with zinc coating on gravel impact does not damage the protective coating and it does not have a significant impact to cause guide mechanical weakening or intensify corrosion phenomena.

- Corrosive endangering of samples made of barrier guide does not significantly affect the deterioration of their mechanical properties, regardless of the duration of the exposures.

- Mechanical damage to samples (cuts, holes) reduces tensile strength, in proportion to reduction of samples' cross-section.

- The mechanical properties of the samples taken from rope barrier wires do not depend on the corrosion exposure time. A small impact of corrosive exposure was observed on reducing (about 3.6\%) the tensile strength of wires subjected to preloading fatigue.

This work was supported by the National Centre for Research and Development and the General Director for National Roads and Motorways - research programme "Development of Road Innovations", project RID 3B (agreement no. DZP/RID-I-64/12/NCBR/2016) in the framework of the LifeRoSE Project. 


\section{References}

1. ASTM D3170-12. Standard Test Method for Chipping Resistance of Coatings, www.astm.org (ASTM International, West Conshohocken, PA, 2012)

2. SAE J400_201210. Test for Chip Resistance of Surface Coatings (SAE International, 2012)

3. GMW14700. Stone Impact Resistance of Coatings (General Motors Worldwide Engineering Standards, n.d.)

4. ISO 21207:2004. Corrosion tests in artificial atmospheres - Accelerated corrosion tests involving alternate exposure to corrosion-promoting gases, neutral salt-spray and drying (International Organization for Standardization, 2004)

5. PN-EN ISO 6892-1:2010 Metale - Próba rozciągania - Część 1: Metoda badania w temperaturze pokojowej (The Polish Committee for Standarization, 2010) 